\title{
Síntese e caracterização de membrana de colágeno associado a compostos de urucum (Bixa orellana L.) para utilização em Regeneração Óssea Guiada
}

\author{
Synthesis and characterization of collagen membrane associated with annatto compounds \\ (Bixa orellana L.) for use in Guided Bone Regeneration
}

\section{Síntesis y caracterización de membrana de colágeno asociada a compuestos de urucum (Bixa orellana L.) para su uso en la Regeneración Ósea Guiada}

\author{
Tarcilio Lima de Sousa ${ }^{1 *}$, Jairelda Sousa Rodrigues ${ }^{1}$ Karinne Sousa de Araújo1.
}

\section{RESUMO}

Objetivo: Sintetizar membranas de colágeno associado a compostos de urucum (Bixa orellana L.) com características físico-macroscópicas análogas às utilizadas no processo de Regeneração Óssea Guiada. Métodos: Foram sintetizadas membranas compostas de amido, colágeno e extrato de urucum. Após a síntese, as membranas foram caracterizadas quanto à cor, translucidez, textura, flexibilidade, espessura e degradação simulada in vitro. Os dados foram organizados de forma discursiva e classificados de acordo com as características apresentadas pelas membranas, sendo correlacionadas com a sua importância mediante relatos na literatura. Resultados: As membranas obtidas apresentaram aspecto translúcido sugestivo da presença de poros, de coloração alaranjada característica do extrato de urucum, superfície lisa demonstrando homogeneidade dos compostos, flexibilidade, espessura fina, o que facilita seu manuseio, e perda gradativa de massa ao longo de 20 dias se comportando de forma favorável à sua utilização. Conclusão: Foram sintetizadas membranas de colágeno associado a compostos de urucum (Bixa orellana L.) translúcidas, com superfície lisa, flexíveis, delgadas, de fácil manipulação e degradáveis ao serem hidratadas, sendo compatíveis para emprego na técnica de Regeneração Óssea Guiada (ROG).

Palavras-chave: Regeneração tecidual guiada, Membranas artificiais, Bixa orellana.

\section{ABSTRACT}

Objective: Synthesize collagen membranes associated with annatto compounds (Bixa orellana L.) with physicalmacroscopic characteristics analogous to those used in the Guided Bone Regeneration process. Methods: Membranes composed of starch, collagen and annatto extract were synthesized. After synthesis, the membranes were characterized for color, translucency, texture, flexibility, thickness and degradation simulated in vitro. The data were organized in a discursive way and classified according to the characteristics presented by the membranes, being correlated with their importance through reports in the literature. Results: The membranes obtained showed a translucent aspect suggestive of the presence of pores, with an orange color characteristic of the annatto extract, a smooth surface demonstrating the homogeneity of the compounds, flexibility, thin thickness, which facilitates its handling, and gradual loss of mass over 20 days if behaving in a way favorable to its use. Conclusion: Collagen membranes associated with annatto compounds (Bixa orellana L.) were synthesized, translucent, with smooth, flexible, thin surfaces, easy to handle and degradable when hydrated, being compatible for use in the Guided Bone Regeneration (ROG) technique.

Keywords: Guided tissue regeneration, Artificial membranes, Bixa orellana.

\section{RESUMEN}

Objetivo: Sintetizar membranas de colágeno asociadas a compuestos de urucum (Bixa orellana L.) con características físico-macroscópicas análogas a las utilizadas en el proceso de Regeneración Ósea Guiada. Métodos: Se sintetizaron membranas compuestas por almidón, colágeno y extracto de urucum. Después de la síntesis, las membranas se caracterizaron por color, translucidez, textura, flexibilidad, espesor y degradación simulada in vitro. Los datos fueron organizados de manera discursiva y classificados de acuerdo con las características que presentan las membranas, siendo correlacionadas con su importancia por medio de relatos en la literatura. Resultados: Las membranas obtenidas mostraron un aspecto traslúcido sugestivo de la presencia de poros, color anaranjado característico del extracto de urucum, una superficie lisa que demuestra la homogeneidad de los compuestos, flexibilidad, espesor fino, que facilita su manipulación, y pérdida gradual de masa sobre 20 días, comportándose de forma favorable a su uso. Conclusión: Se sintetizaron membranas de colágeno asociadas a compuestos de urucum (Bixa orellana L.) translúcidas, con superficies lisas, flexibles, delgadas, fáciles de manipular y degradables al hidratarse, siendo compatibles para su uso en la técnica de Regeneración Ósea Guiada (ROG).

Palabras clave: Regeneración tejido guiada, Membranas artificiales, Bixa orellana.

${ }^{1}$ Centro Universitário UniFacid, Teresina - PI. *E-mail: tarciliosousa@outlook.com 


\section{INTRODUÇÃO}

A regeneração óssea é uma das abordagens mais importantes e desafiadoras da engenharia de tecidos na medicina regenerativa, sendo uma técnica promissora em odontologia por ser considerada uma estratégia ideal para o tratamento de doenças, lesões e defeitos ósseos na região maxilofacial. Na Regeneração Óssea Guiada (ROG), a membrana que recobre o defeito ósseo desempenha papéis importantes, como selar o sítio cirúrgico e prevenir que outros tecidos interfiram na osteogênese e na orientação do processo de formação óssea. Tais características afetam significativamente o resultado do tratamento de reparação óssea (WUBNEH A, et al., 2018).

O tecido ósseo tem uma capacidade notável de regenerar e curar a si mesmo. Defeitos ósseos resultantes de trauma, infecção, tumores ósseos ou malformação congênita são considerados desafios cirúrgicos sérios na medicina e na odontologia. As membranas biológicas estão indicadas em casos de defeitos periodontais, lugares de extração, osso insuficiente para colocação de implante ou aparelho protético (COSTA JBZ, et al., 2016).

Os defeitos ósseos são divididos em pequenos e grandes defeitos ósseos. Pequenos defeitos ósseos sem infecção são capazes de cicatrizar espontaneamente por desbridamento, enquanto grandes defeitos ósseos necessitam de tratamentos cirúrgicos. Atualmente, os principais métodos de tratamento para grandes defeitos ósseos são a utilização de enxertos autólogos, enxertos alógenos ou substitutos de enxerto ósseo. No entanto, as desvantagens das etapas de tratamento complexas e altas taxas de rejeição de enxerto significam que as aplicações práticas permanecem limitadas (WANG Y, et al., 2021).

Nos últimos anos, a engenharia de tecidos como uma abordagem alternativa para reparar defeitos, tem recebido atenção crescente. Na sua prática, a engenharia de tecidos ósseos, envolve o uso de células, estruturas e fatores de crescimento para orientar a formação de ossos. Diferentes biomateriais são incorporados a substâncias estimuladoras, que são implantados em defeitos ósseos para promoverem a regeneração de ossos (WUBNEH A, et al., 2018)

O desenvolvimento de técnicas e biomateriais para utilização na Odontologia tem resultado em grande avanço biotecnológico e clínico, especialmente nas correções de defeitos ósseos extensos. Várias técnicas e materiais foram desenvolvidos nos últimos anos para a prática da ROG. Por meio desta técnica é possível manter as dimensões ósseas ou reduzir a gravidade dos defeitos após cirurgias, devido ao uso de membranas que atuam como verdadeiras barreiras (SASAKI J, et al., 2021).

Dois tipos de membranas são usados nas terapias de ROG: não-reabsorvíveis e reabsorvíveis. As primeiras desenvolvidas para utilização foram as não-absorvíveis. Elas demandam uma cirurgia subsequente para sua remoção e estão frequentemente associadas à exposição no sítio cirúrgico, que, consequentemente, pode comprometer o sucesso clínico. A membrana com essas características mais pesquisada e utilizada em procedimentos de ROG é constituída por uma estrutura formada por politetrafluoroetileno expandido (ePTFE). No intuito de suprimir a necessidade de um segundo tempo cirúrgico para a remoção da membrana não-absorvível, tem sido intensa a investigação para o desenvolvimento de membranas absorvíveis (DA SILVEIRA GERZSON A, et al., 2016).

As membranas reabsorvíveis foram elaboradas para eliminar a necessidade de um segundo procedimento cirúrgico para sua remoção, já que as mesmas são degradadas pelo processo de hidrólise, gerando substâncias químicas comuns para os processos metabólicos normais (DA SILVEIRA GERZSON A, et al., 2016). Estas membranas devem apresentar biocompatibilidade e exercer a sua função de exclusão celular de tecidos indesejáveis, promovendo o espaço para o crescimento ósseo. Além disso, a eficácia clínica também depende da sua capacidade de manter sua integridade estrutural durante as primeiras semanas e de ser gradualmente biodegradada após este período (BOTTINO MC, et al., 2011).

De acordo com Dimitriou R, et al. (2012), as membranas reabsorvíveis podem ser categorizadas em três grupos de acordo com sua composição: naturais, à base de colágeno; naturais, à base de quitosana; e sintéticas, à base de poliésteres alifáticos, como por exemplo ácido polilático e ácido poligligólico. As membranas reabsorvíveis a base de colágeno, são amplamente estudadas e utilizadas atualmente (PEREIRA JC, 2017). 
O colágeno tem demonstrado ser superior a outros materiais utilizados para a construção de membranas bioativas, por ser um importante componente do tecido conjuntivo, apresentar bom desempenho na formação do coágulo, responder à quimiotaxia e ter facilidade de associação com outros compostos ativos (SHEIKH Z, et al., 2017).

A utilização do colágeno na produção de materiais com aplicações biomédicas tem sido ampla nos últimos anos, visto que apresenta grande abundância na natureza, biocompatibilidade, estabilidade, alta porosidade, facilidade de combinação com outros materiais, fácil processamento, baixa antigenicidade e capacidade de absorção no corpo. Tornando-se uma matéria prima de excelente escolha para a produção de biomateriais de diferentes formas e aplicabilidade, como membranas e esponjas para revestimento de queimaduras, géis para hemostasia e suporte para o crescimento de células (PIRES ALR, et al., 2015; FAUZI MB, et al, 2016)

Pesquisas têm demonstrado a utilização de produtos naturais a fim de favorecer o processo de reparação óssea (BLOKHUIS TJ e ARTS JJC, 2011; GARCIA-GARETA E, et al., 2015; SANTOS JAA, et al. 2014). Relatos da história antiga, apontam que plantas medicinais foram utilizadas pelas civilizações primitivas com o intuito de cura e tratamento de doenças (BADKE MR, et al., 2011). Atualmente, considera-se que esse é um recurso terapêutico acessível, disponível e culturalmente aceito na medicina popular (CORELLDOMÉNECH M, 2019).

A Bixa orellana L. é uma planta nativa do Brasil, conhecida popularmente por urucum e sua utilização é extensamente disseminada na cultura brasileira, particularmente na alimentação. Mas, também, é utilizada na medicina popular para o tratamento de diabetes, infecções cutâneas, queimaduras, febre, diarreia, asma, dentre outros (CAPELLA SO, et al., 2016). Suas sementes são uma rica fonte de pigmentos alaranjados compostos por uma mistura de carotenoides, como a bixina, norbixina e b-caroteno (SILVA ZS, et al., 2020).

Os carotenoides extraídos do urucum compõem uma conhecida classe de antioxidantes naturais que podem atuar como sequestradores de radicais livres inibindo a propagação da reação em cadeia tanto in vitro quanto in vivo (KAULMANN A e BOHN T, 2014).

Estudos realizados por Capella SO, et al. (2016) revelaram que a utilização de extrato oleoso da semente de urucum (Bixa orellana L.) é capaz de acelerar as fases iniciais da cicatrização de feridas cutâneas. Pesquisas in vitro e in vivo demonstraram que os carotenoides têm propriedades antioxidante, anti-apoptótica e anti-inflamatória (KAULMANN A e BOHN T, 2014). Além disso, os carotenoides têm apresentado efeito benéfico no osso, tanto na atividade osteoclástica quanto modulando os osteoblastos in vitro (SILVA ZS, et al., 2020).

Diversos trabalhos têm demonstrado a utilização de biomateriais a fim de favorecer o processo de reparação óssea (MAREW T e BIRHANU G, 2021; VACARAS S, et al., 2021). No entanto, não foram descritas na literatura pesquisas que explorem a utilização de compostos do urucum associado ao colágeno para aplicação em reparação óssea na técnica de ROG. Diante desta perspectiva, ressalta-se a relevância de pesquisa que demonstre a síntese de uma membrana reabsorvível, constituída de colágeno associado a compostos de urucum (Bixa orellana L.) para a aplicação na reparação óssea em modelo experimental, com grande potencial para aplicações biotecnológicas (ARAÚJO KS, 2018).

O objetivo do presente estudo foi sintetizar membranas de colágeno associado a compostos de urucum (Bixa orellana L.) com características físico-macroscópicas análogas às utilizadas em Regeneração Óssea Guiada.

\section{MÉTODOS}

A síntese da membrana colagenosa associada a compostos de urucum foi realizada em quatro etapas: produção do filme resinoso, preparo da solução ácida de colágeno, preparo da solução ácida de urucum e preparo do compósito.

Para a produção do filme resinoso, foi pesado $6 \mathrm{~g}$ de amido, que foi misturado a $100 \mathrm{ml}$ de água destilada em béquer de $500 \mathrm{ml}$. Em seguida, foram levados à uma chapa aquecedora com controle de temperatura, formando um composto denominado "cola". 
Para que fossem obtidas as propriedades de flexibilidade e elasticidade favoráveis à membrana, foi produzido uma solução ácida de colágeno liofilizado em ácido acético, na concentração de $0,05 \mathrm{~g} / \mathrm{ml}$. Misturouse em temperatura ambiente até que o composto se tornou homogêneo.

Com o intuito de diluir o extrato seco das sementes do urucum, misturou-se $0,5 \mathrm{~g}$ do pó de urucum em $50 \mathrm{ml}$ de ácido acético em um balão volumétrico de $100 \mathrm{ml}$. Deixando que a diluição ocorresse em temperatura ambiente no período de 24 horas.

Para a preparação do compósito, foram misturados $7,5 \mathrm{~g}$ da cola (amido e água destilada) e $2,5 \mathrm{~g}$ da solução ácida de colágeno em um béquer de $500 \mathrm{ml}$, formando uma resina polimérica. Em seguida, foram adicionados $5 \mathrm{~g}$ desta resina a $5 \mathrm{~g}$ da solução ácida de urucum (proporção massa/massa), até a obtenção de uma mistura homogênea.

Em seguida, o compósito obtido foi distribuído em 9 (nove) placas de Petri estéreis e descartáveis. As placas permaneceram abertas por 3 dias, em temperatura ambiente, para que ocorresse a evaporação das substâncias voláteis e solidificação da resina, para então formar as membranas.

Para início da caracterização das membranas, foram observados os aspectos macroscópicos relacionados à translucidez, cor e textura (presença de bolhas e/ou presença de partículas insolúveis).

Para verificação da espessura das membranas, foi utilizado um paquímetro analógico, com precisão de $1 \mathrm{~mm}$. Em cada amostra, foram medidos cinco pontos, totalizando 45 medidas. As membranas também foram avaliadas quanto às suas propriedades mecânicas baseada em flexibilidade.

A fim de reproduzir o comportamento das membranas em meio biológico e verificar sua degradação, foi adicionada quantidade padronizada de $5 \mathrm{ml}$ de soro fisiológico em cada placa de Petri. A degradação das amostras foi verificada diariamente, durante o período de 20 dias, por meio de manipulação com o auxílio de uma espátula.

Os dados foram organizados de forma discursiva e classificados de acordo com as características físicomacroscópicas apresentadas pelas membranas, sendo correlacionadas essas características à sua importância mediante relatos na literatura.

\section{RESULTADOS E DISCUSSÃO}

Com base na metodologia proposta neste trabalho, foram obtidas nove membranas de colágeno associado a compostos de urucum. Quanto aos aspectos macroscópicos, observou-se que essas eram translúcidas. Segundo Nielen WM, et al. (2021), é provável que a característica de translucidez seja resultante da presença de poros, justificada macroscopicamente ao efeito da passagem de luz que consegue atravessar o corpo da membrana, que só são possíveis serem avaliados microscopicamente. Os poros são decorrentes da variação no tempo de evaporação dos solventes utilizados nesse estudo, ácido acético e água. $O$ ácido acético evapora-se mais rapidamente do que a água, promovendo dois efeitos: aumento no tempo de coalescência das substâncias, levando a separação de fases, e o aumento da concentração de água na estrutura polimérica (Figura 1).

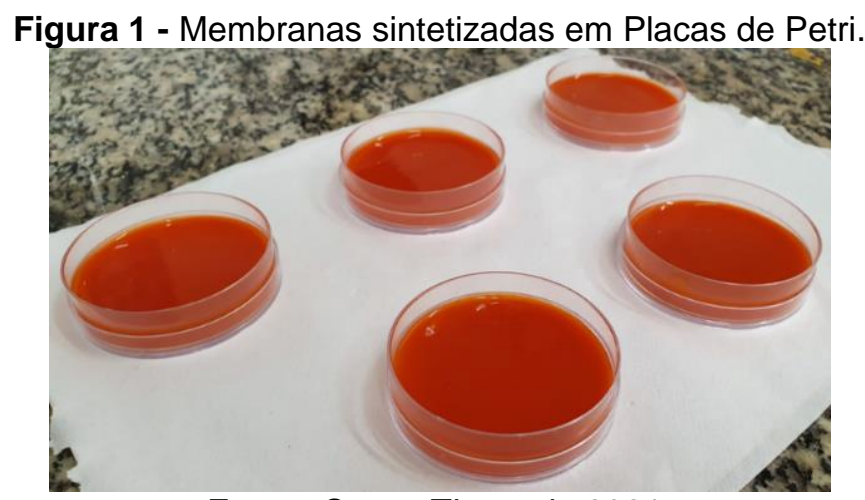

Fonte: Sousa TL, et al., 2021. 
A porosidade alcançada nas membranas é uma característica importante para sua utilização em processos regenerativos. Pois, permite a difusão de fluídos sanguíneos através da mesma, porém os poros devem ser menores do que as células dos tecidos indesejáveis, de forma que a membrana impeça a passagem de células, como os fibroblastos, para a área do defeito a ser regenerado (ZHOU L, et al., 2015).

A existência dos poros na estrutura das membranas permite um certo fluxo de nutrientes, oxigênio, fluidos e substâncias bioativas através da mesma, porém os poros devem ser menores do que as células dos tecidos indesejáveis, de forma que a membrana impeça a passagem desses tecidos para a área do defeito a ser regenerado (BENETTI LP, 2020).

Os poros são espaços vazios presentes no material da membrana, podendo apresentar forma circular ou não, ser abertos ou fechados ou formar uma rede contínua e interligada. O tamanho deles e sua distribuição determinam quais moléculas ou partículas são retidas pela membrana e quais permeiam através de seus poros. A membrana mais adequada para qualquer aplicação deve apresentar um grande número de poros com menor tamanho possível dentro de sua faixa de separação, de forma que o menor tamanho do poro favorece o alto percentual de retenção, enquanto que um grande número de poros favorece o alto fluxo de permeado (FARIA PC, et al., 2017).

Embora a porosidade ideal ainda não tenha sido elucidada, acredita-se que um maior índice de porosidade (em torno do 80-88\%) seria benéfico para o crescimento ósseo. Isso pode estar relacionado com a diminuição na atividade contra corpos estranhos de acordo com o tamanho em que os poros são aumentados. No entanto, um aumento no tamanho do poro em si (devido à degradação da membrana) pode afetar na bioatividade e no crescimento de tecido duro e mole (SANZ M, et al., 2019).

No que se refere à coloração, as membranas apresentaram cor alaranjada. Esta característica é decorrente da presença de bixina, pigmento alaranjado, que representa mais de $80 \%$ dos carotenóides totais extraídos da camada externa das sementes de Bixa orellana L. (GARCIA CER, et al., 2012).

Em relação à sua textura, não foram observadas bolhas ou partículas insolúveis nas superfícies das membranas, dando um aspecto liso e homogêneo. Tais características favorecem a implantação no sítio cirúrgico, evitando irritação superficial da área lesada (ARTZI Z, 2020). É provável que a superfície lisa e brilhante das membranas seja consequência do ácido acético, o qual foi utilizado como solvente para a preparação das soluções ácidas nesse estudo. De acordo com Lavra M e Maria Z (2016), a homogeneidade no processo de união de compostos está relacionada com a escolha do solvente empregado nas preparações (Figura 2).

Figura 2 - Superfície da membrana sintetizada.

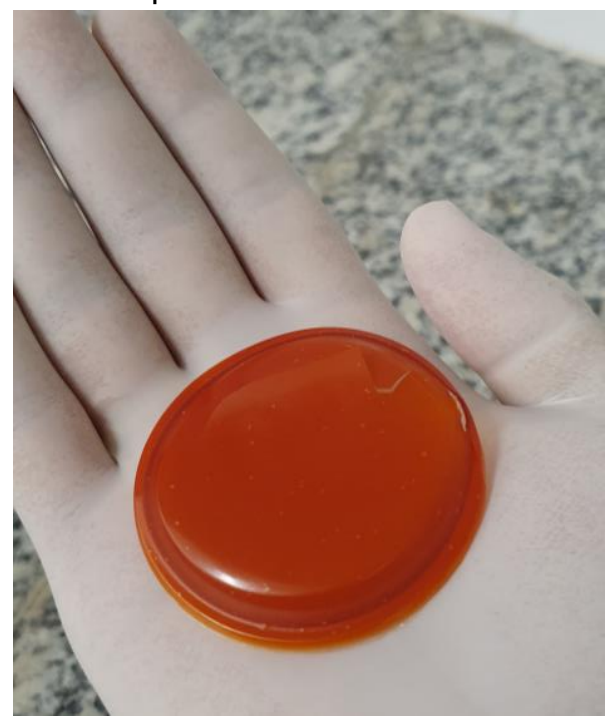

Fonte: Sousa TL, et al., 2021. 
De acordo com Artzi Z (2020) a rugosidade da superfície é um fator que pode influenciar na adesão e proliferação celular e formação óssea. Como exemplo, uma superfície interna de hidroxiapatita, moderadamente rugosa, produz regeneração óssea significativamente maior do que superfícies mais lisas. Isto ocorre porque os osteoblastos exibem uma maior afinidade para superfícies mais ásperas e porosas (ANDERUD J, et al., 2016).

Para síntese das membranas, foram adicionados manualmente $10 \mathrm{~g}$ do compósito em cada placa de Petri, a fim de padronizar suas dimensões. Ao analisar cada membrana isoladamente, foi possível observar pelos valores obtidos, que elas apresentaram a espessura média de $1 \mathrm{~mm}$ ao longo de sua dimensão. A espessura das membranas é definida como a distância perpendicular entre duas superfícies principais. Conhecendo-se a espessura, é possível obter informações sobre a resistência mecânica e as propriedades de barreira do material. O controle da espessura é importante para se avaliar a uniformidade desses materiais, a repetibilidade da medida de suas propriedades e a validade das comparações entre as membranas (RODRÍGUEZ FJ, et al., 2012).

Porém, a espessura final das membranas varia de acordo com a evaporação do solvente, já que o controle da mesma depende do microambiente. No caso de possuir aditivos que interagem de forma diferente com o solvente e com a matriz, pode ocorrer um aumento ou diminuição da espessura, e de outras propriedades da membrana. Isso leva a uma cinética diferente de evaporação do solvente, sobretudo quando se incorpora os aditivos em sua composição (BORGES MF, 2018).

Analisando cada membrana individualmente, observou-se que sua espessura não variou ao longo de sua superfície. Logo, as membranas apresentam boa homogeneidade em termos de espessura, visto que diferentes pontos apresentam valores idênticos.

Observou-se que as membranas sintetizadas eram flexíveis, sendo quebradas apenas quando submetidas ao dobramento. Segundo Borges MF (2018), em relação a aplicação das membranas em processos regenerativos, uma das características básicas para se utilizá-las como barreira é sua capacidade de manutenção de espaço adequado para a regeneração. Deste modo, as membranas devem apresentar características mecânicas que permitam que ela suporte forças exercidas pelas tensões dos tecidos lesados na ferida cirúrgica, prevenindo o colapso da mesma sobre o defeito (Figura 3).

Figura 3 - Flexão da membrana.

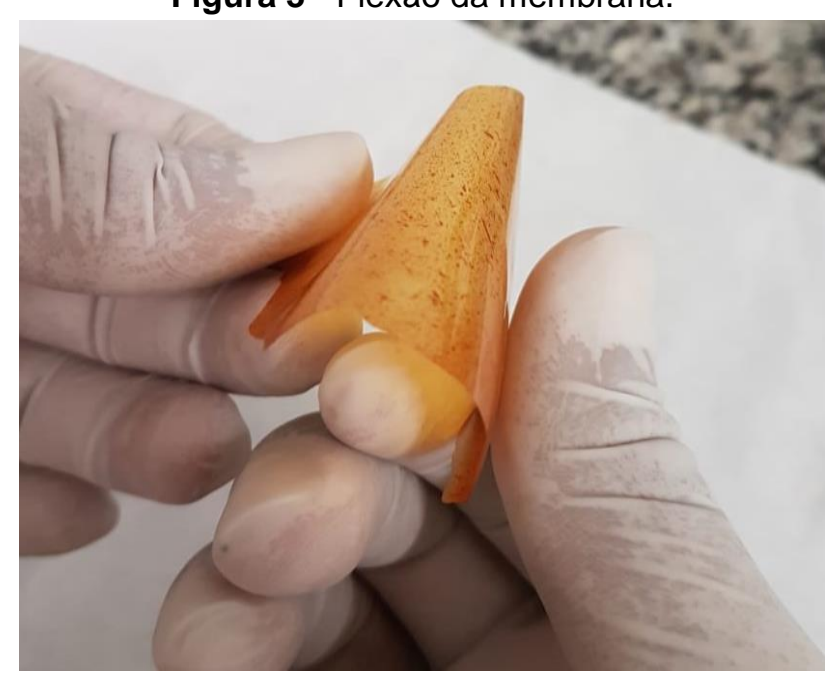

Fonte: Sousa TL, et al., 2021.

Com o intuito de simular o meio biológico, cada membrana foi hidratada com $5 \mathrm{ml}$ de solução fisiológica e permaneceu na placa de Petri durante o período de 20 dias para verificação de sua degradação. Percebeuse que, após a hidratação, as membranas estavam maleáveis e puderam ser manipuladas sem dificuldade. Porém, observou-se uma perda gradativa de sua massa ao longo do período de observação (Figura 4). 
Figura 4 - Membrana hidratada em meio fisiológico.

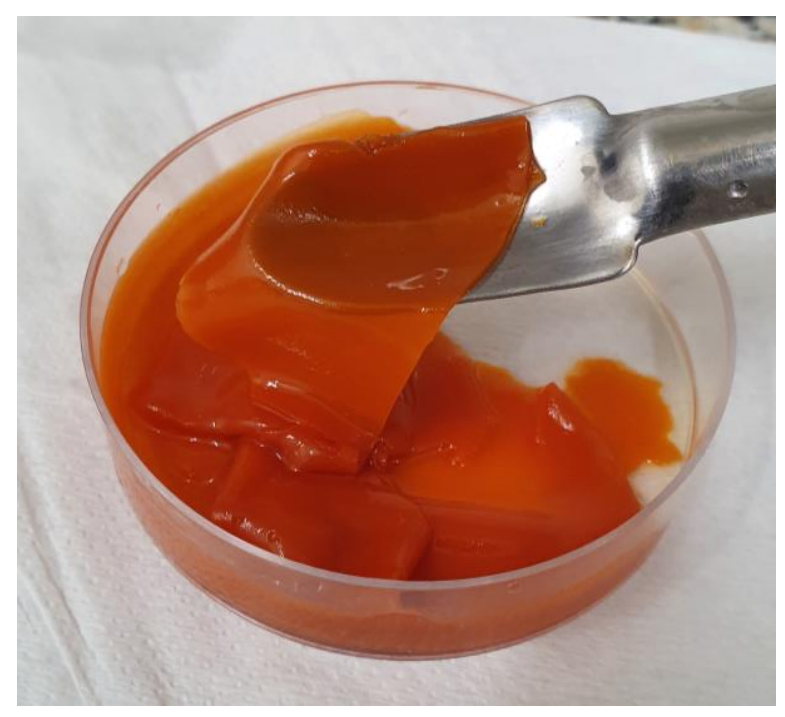

Fonte: Sousa TL, et al., 2021.

Uma das principais características das membranas usadas em ROG é que eles devem ser capazes de manter um espaço por um período de tempo suficiente para permitir a regeneração óssea. A membrana ideal deve ser rígida o suficiente para gerar o referido espaço e suportar a pressão dos tecidos adjacentes para evitar o seu colapso, embora deva ter alguma elasticidade e plasticidade para se adaptar ao defeito. A capacidade da membrana de suportar forças de elasticidade e resistência de compressão, deve ser equivalente àquelas da zona do defeito em que o referido material é inserido (ELGALI I, et al., 2016; PRASADH S e WONG RCW, 2018).

Segundo Chang H, et al. (2017) e Guarnieri R, et al. (2017), a resistência mecânica e o comportamento de degradação da membrana são de extrema importância para o sucesso da regeneração do tecido, sendo fatores determinantes no processo de formação óssea. Se a degradação do biomaterial ocorrer prematuramente, pode ocasionar perda da estabilidade dimensional, dissipação do enxerto, além de comprometer a cicatrização no local da cirurgia; se ocorrer tardiamente, causa uma cicatrização defeituosa.

Quando se projeta uma membrana para ROG, é necessário que esta mantenha a sua integridade durante um período de cerca de 4 a 6 semanas para que haja completa regeneração óssea (BOTTINO MC, et al., 2011). Quanto mais tempo a membrana for capaz de manter sua função, melhor será o prazo para obtenção de quantidade de osso maduro. Além disso, os produtos residuais do processo de reabsorção da membrana não devem afetar o processo de resposta inflamatória (SANZ M, et al., 2019).

Como houve perda gradativa de massa das membranas sintetizadas nesse estudo, é possível classificálas como degradável. Essa característica é uma propriedade importante de membranas reabsorvíveis utilizadas na técnica de ROG, visto que não é necessário um segundo tempo cirúrgico para a sua remoção. No entanto, o potencial in vivo deve ser corroborado com análises complementares em experimentos com animais (BORGES MF, 2018).

Neste trabalho foram possíveis serem analisadas características físico-macroscópicas das membranas de urucum que, comparadas à literatura contemporânea das membranas utilizadas na técnica de ROG, comprovassem que as sintetizadas neste estudo, fossem passíveis de compatibilidade com o seu emprego na técnica de ROG. Ao mesmo tempo que, é sugerida a realização de ensaios biológicos que executem a técnica de ROG, visando a verificação dos efeitos das membranas sintetizadas, para assim demonstrar os seus benefícios no processo de reparação óssea. Da mesma forma, propõe-se que sejam realizados ensaios laboratoriais capazes de caracterizar as membranas de urucum de acordo com suas caraterísticas físicoquímicas e que analisem seu desempenho a longo prazo. 


\section{CONCLUSÃO}

De acordo com a metodologia aplicada nesse estudo, foram sintetizadas membranas de colágeno associado a compostos de urucum (Bixa orellana L.) translúcidas, com superfície lisa e homogênea, flexíveis, delgadas, de fácil manipulação e degradáveis ao serem hidratadas. Estas características físicomacroscópicas são compatíveis para uso na técnica de Regeneração Óssea Guiada (ROG). No entanto, recomenda-se a realização de testes adicionais no intuito de caracterizar as membranas quanto às suas propriedades físico-químicas. Da mesma forma, sugere-se a realização de ensaios biológicos que visem verificar os efeitos das membranas sintetizadas na técnica de ROG, para assim demonstrar os seus benefícios no processo de reparação óssea.

\section{AGRADECIMENTOS}

À instituição de ensino Centro Universitário UniFacid por proporcionar o espaço e o incentivo à pesquisa no âmbito da graduação, bem como aos técnicos dos laboratórios que se dispuseram e se prontificaram para auxiliar no andamento dos experimentos in vitro.

\section{REFERÊNCIAS}

1. AGARWAL R, GARCíA AJ. Biomaterial strategies for engineering implants for enhanced osseointegration and bone repair. Advanced drug delivery reviews, 2015; 94: 53-62.

2. ANDERUD J, et al. The impact of surface roughness and permeability in hydroxyapatite bone regeneration membranes. Clinical oral implants research, 2016; 27(8): 1047-1054.

3. ARAÚJO KS. Reparação óssea com utilização de colágeno e compostos de urucum (Bixa orellana L.) em Rattus norvegicus. Tese (Doutorado em Biotecnologia) - Rede Nordeste de Biotecnologia. Universidade Federal do Piauí, Teresina, 2018.

4. ARTZI Z. Bone Augmentation by Anatomical Region: Techniques and Decision-making. New York: John Wiley \& Sons, 2020; 560p.

5. BADKE MR, et al. Plantas medicinais: o saber sustentado na prática do cotidiano popular. Escola Anna Nery, 2011; 15(1): 9-132.

6. BENETTI LP. Avaliação da regeneração óssea guiada por meio do uso de membrana de colágeno bovino associada à hidroxiapatita em defeitos críticos na calvária de ratos. Análises histomorfométrica e imunoistoquímica. Dissertação (Mestrado em Odontologia) - Universidade Estadual Paulista. Faculdade de Odontologia de Araçatuba, Araçatuba, 2020; 49p.

7. BLOKHUIS TJ, ARTS JJC. Bioactive and osteoinductive bone graft substitutes: Definitions, facts and myths. Int. J. Care Injured., 2011; 42: 26-29.

8. BORGES MF. Desenvolvimento de membranas de acetato de celulose incorporadas com aditivos funcionais para tratamentos regenerativos periodontais. Dissertação (Mestrado em Química). Universidade Federal de Uberlândia, Uberlândia, 2018; 94 p.

9. BOTTINO MC, et al. A novel spatially designed and functionally graded electrospun membrane for periodontal regeneration. Acta biomaterialia, 2011; 7(1): 216-224.

10. CAPELLA SO, et al. Potencial cicatricial da Bixa orellana L. em feridas cutâneas: estudo em modelo experimental. Arquivo Brasileiro de Medicina Veterinária e Zootecnia, 2016; 68(1): 104-112.

11. $\mathrm{CHANG} \mathrm{H}$, et al. Comparative, randomized, double-blind clinical study of alveolar ridge preservation using an extracellular matrix-based dental resorbable membrane in the extraction socket. Journal of periodontal \& implant science, 2017; 47(3): 165-173.

12. CORELL-DOMÉNECH M. Terapeutas alternativos en México y la estrategia de la OMS sobre medicina tradicional 2014-2023: comunicación, creencias y factores socio-económicos. Perspectivas de la comunicación, 2019; 12(1): 5977.

13. COSTA JBZ, et al. O uso de membranas biológicas para regeneração óssea guiada em implantodontia: uma revisão de literatura. Revista Bahiana de odontologia, 2016; 7(1): 14-21.

14. DA SILVEIRA GERZSON A, et al. Membranas para barreira utilizadas em ROG: características e indicações. Journal of Clinical Dentistry \& Research, 2016; 13(4).

15. DIMITRIOU R, et al. O papel das membranas de barreira para a regeneração óssea guiada e restauração de grandes defeitos ósseos: evidências experimentais e clínicas atuais. Medicina BMC, 2012; 10(1): 1-24. 
16. ELGALI I, et al. Guided bone regeneration: materials and biological mechanisms revisited. European journal of oral sciences, 2017; 125(5): 315-337.

17. FARIA, PC, et al. Caracterização no Infravermelho (IV) e Eletrônica de superfície (MEV) de membranas assimétricas à base de Poli (acrilonitrila-co-acetato de vinila). Matéria (Rio de Janeiro), 2017; 22(1).

18. FAUZI MB, et al. Ovine tendon collagen: Extraction, characterisation and fabrication of thin films for tissue engineering applications. Materials Science and Engineering: C, 2016; 68: 163-171.

19. GARCIA CER, et al. Carotenoides bixina e norbixina extraídos do urucum (Bixa orellana L.) como antioxidantes em produtos cárneos. Ciência Rural, 2012; 42(8): 1510-1517.

20. GARCIA-GARETA E, et al. Osteoinduction of bone grafting materials for bone repair and regeneration. Bone, 2015; 81: 112- 121.

21. GUARNIERI R, et al. Extraction socket preservation using porcine-derived collagen membrane alone or associated with porcine-derived bone. Clinical results of randomized controlled study. Journal of oral \& maxillofacial research, $2017 ; 8(3)$.

22. KAULMANN A, BOHN T. Carotenoids, inflammation, and oxidative stress - implications of cellular signaling pathways and relation to chronic disease prevention. Nutr Res., 2014; 34(11): 907-929.

23. LAVRA M, MARIA Z. Incremento da solubilidade e da cinética de dissolução do fármaco Efavirenz através da obtenção de misturas binárias amorfas com matrizes poliméricas. Tese (Doutorado em Engenharia de Processos e Ambiental) - Ecole nationale des Mines d'Albi-Carmaux. Universidade Federal de Pernambuco, Recife, 2016; 253p.

24. MAREW T, BIRHANU G. Three dimensional printed nanostructure biomaterials for bone tissue engineering. Regenerative Therapy, 2021; 18: 102-111.

25. NIELEN WM, et al. Effect of Solution Viscosity on the Precipitation of PSaMA in Aqueous Phase Separation-Based Membrane Formation. Polymers, 2021; 13(11): 1775.

26. PEREIRA JC. Avaliação do processo de reparo em defeitos de calvária de ratos com membrana de celulose bacteriana e membrana de colágeno porcino: análise histológica, histométrica e imunoistoquímica. Tese (Doutorado em Odontologia) - Universidade Estadual Paulista. Faculdade de Odontologia de Araçatuba, Araçatuba, 2017; 41p.

27. PIRES ALR, et al. Biomateriais: tipos, aplicações e mercado. Química nova, 2015; 38(7): 957-971.

28. PRASADH S, WONG RCW. Unraveling the mechanical strength of biomaterials used as a bone scaffold in oral and maxillofacial defects. Oral Science International, 2018; 5(2): 48-55.

29. RODRíGUEZ FJ, et al. Modification of cellulose acetate films using nanofillers based on organoclays. Journal of Food Engineering, 2012; 110(2): 262-268.

30. SANTOS JAA, et al. Avaliação histomorfométrica do efeito do extrato aquoso de urucum (norbixina) no processo de cicatrização de feridas cutâneas em ratos. Rev. Bras. PI. Med. 2014; 16(3): 637-643.

31. SANZ M, et al. Biomaterials and regenerative technologies used in bone regeneration in the craniomaxillofacial region: Consensus report of group 2 of the 15th European Workshop on Periodontology on Bone Regeneration. Journal of clinical periodontology, 2019; 46: 82-91.

32. SASAKI J, et al. Barrier membranes for tissue regeneration in dentistry. Biomaterial Investigations in Dentistry, 2021; 8(1): 54-63.

33. SHEIKH Z, et al. Natural graft tissues and synthetic biomaterials for periodontal and alveolar bone reconstructive applications: a review. Biomaterials research, 2017; 21(1): 1-20,

34. SILVA ZS, et al. The effects of photodynamic therapy with blue light and papain-based gel associated with Urucum, on collagen and fibroblasts: a spectroscopic and cytotoxicity analysis. Lasers in medical science, 2020; 35(3): 767-775.

35. VACARAS S, et al. Engaging a polylactide copolymer in oral tissue regeneration: first validation of Suprathel® for guided epithelial and osseous healing. Journal of Medicine and Life, 2021; 14(2): 181.

36. WANG $Y$, et al. Copper-based biomaterials for bone and cartilage tissue engineering. Journal of Orthopaedic Translation, 2021; 29: 60-71.

37. WUBNEH A, et al. Estado atual das tecnologias de fabricação e materiais para engenharia de tecido ósseo. Acta Biomaterialia, 2018; 80: 1-30.

38. ZHOU L, et al. Biofunctionalization of microgroove titanium surfaces with an antimicrobial peptide to enhance their bactericidal activity and cytocompatibility. Colloids and Surfaces B: Biointerfaces, 2015; 128(1): 552-560. 